\title{
Genotyping of High Yielding Varieties and Genotypes of Turmeric (Curcuma longa L.) using RAPD Markers
}

\author{
Mikias Damtew (Mikias D.G.) ${ }^{1}$, Shoba Natarajan (N. Shoba) ${ }^{2}$, Sekar Makesh (S. \\ Makesh) ${ }^{3}$ \\ ${ }^{I}$ Department of Horticulture, Ethiopian Institute of Agricultural Research, Addis Ababa, Ethiopia \\ ${ }^{2}$ Horticultural College and Research Institute, Tamil Nadu Agricultural University, Coimbatore, India \\ ${ }^{3}$ Horticultural College and Research Institute, Tamil Nadu Agricultural University, Coimbatore, India
}

\begin{abstract}
In the study four released varieties and six high yielding turmeric clones were genotyped using fifteen RAPD markers to see band amplification patterns and genetic variations. Jaccard's coefficient method was used as an estimator of genetic identity and similarity among the genotypes and UPGMA (un-weighted pair group method, arithmetic average) utilized for clustering the genotypes. All the fifteen RAPD primers produced clear polymorphic amplification for the turmeric genotypes used in the study resulting 68 RAPD bands of which 59 bands were polymorphic with average polymorphism of $86.76 \%$. Jaccard's similarity between genotypes pairs ranged between 0.36 and 0.93 with a mean of 0.62 . Prominent difference was observed between the genotypes with BSR-1 and PTS-8. The genotype CL-101 and CL-193 recorded the highest similarity index (0.93) followed by the combination BSR-2 and CL-101 (0.89). The lowest average similarity index was recorded by the variety BSR-1 (0.49) followed by PTS-8 (0.54) and CL-219 (0.58). The RAPD marker result depicted that the use of such molecular marker tool could be a viable option in the presence of a validated marker system developed for identification of the genotypes.
\end{abstract}

Keywords: Turmeric, genetic diversity, RAPD markers

\section{INTRODUCTION}

Turmeric (Curcuma longa L.), probably a native of Southeast Asia, is an ancient spice and modern medicine is gaining pristine importance worldwide (Roses, 1999). It is widely used as a dietary spice, coloring agent in food, source of phenolic compounds, curcuminoids and is widely used as a medicine in most Asian countries. Recently, it has attracted much attention due to its significant medicinal potential due to the presence of several potent antioxidant compounds (Cousins et al., 2007). Due to the crop economic importance several studies on its genetics has been implemented for successful breeding objectives and conservation of plant genetic resources efficiently.

Morphological studies by several authors have indicated a high degree of variability in turmeric germplasm in India (Chandra et al., 1997; Kurian and Nair 1996; Philip and Nair 1983). However, the use of only such classical approaches to study variability has several inherent limitations leading to an advent exploitation of molecular markers to analyze intra-specific diversity in many crop species. As a result, the use of molecular markers in species delimitation and study of varietal divergence in the genus RAPD markers assume great significance (Sasikumar and Syamkumar, 2007). In this regard significant genetic variations by RAPD markers have also been reported in other species at cultivar level (Huang et al., 2003). Nayak et al. (2006) demonstrated the utility of using RAPD markers to characterize genetic diversity among 17 promising cultivars of $C$. longa. Similar trends in plant species of tropical origin are also indicated by Hamrick and Loveless (1989) maintaining high genetic diversity within populations.

Hence, the current study was conducted with the objective of investigate the varietal difference among ten high yielding turmeric clones under production in Tamil Nadu state, India. RAPD molecular markers were used for the purpose of this study to discriminate the varietal difference among the turmeric clones. 
Mikias Damtew et al. "Genotyping of High Yielding Varieties and Genotypes of Turmeric (Curcuma Longa L.) using RAPD Markers"

\section{MATERIAL AND METHODS}

The study was conducted at Tamil Nadu Agricultural University, Horticultural College and Research Institute using four released varieties and six high yielding turmeric clones that are collected from Tamil Nadu area. Three plants were raised on pots under greenhouse condition and unrolled young leaf tissues were used for DNA extraction.

\section{DNA Extraction and Purification}

The DNA was isolated from unrolled young leaves weighing 3g using CTAB method (Doyle and Doyle, 1987) with modification (Harini et al., 2008). The CTAB extraction buffer contained 3\% (w/v) CTAB, 3M NaCl, $100 \mathrm{mM}$ Tris.HCl (PH 8.0), 20mM EDTA (PH 8.0) and a freshly added $0.2 \% 2-$ mercaptoethanol. Qualitative analyses of the isolated DNA was done by running the samples on $1 \%$ agarose gel to visualize the intensity of bands and the samples were stored at $4^{\circ} \mathrm{C}$ for RAPD marker studies.

\section{RAPD Amplification}

PCR amplification was performed using fifteen random decamer primers in a BIORAD (Bio-Rad Laboratories, Inc. USA). Reaction volume of $25-\mu$ l containing $2.5 \mu 110 \mathrm{x}$ PCR reaction buffer, 2.0 $\mathrm{mM} \mathrm{MgCl} 2,10 \mathrm{mM}$ each dNTP, 20 pmol RAPD primer, $50 \mathrm{ng}$ genomic DNA, and $0.3 \mathrm{U}$ Taq DNA polymerase were used for amplification. Hot start PCR $\left(95^{\circ} \mathrm{C}\right)$ with an initial denaturation at $94^{\circ} \mathrm{C}$ for 4 min and 40 cycles at $94^{\circ} \mathrm{C}$ for $1 \mathrm{~min}, 37^{\circ} \mathrm{C}$ for $1 \mathrm{~min}, 72^{\circ} \mathrm{C}$ for $1 \frac{1 / 2}{2} \mathrm{~min}$, followed by $10 \mathrm{~min}$ at $72^{\circ} \mathrm{C}$. Then amplified products were separated on $2 \%$ agarose gel in $1 \times$ TBE buffer $(100 \mathrm{mM}$ Tris-HCl, $\mathrm{pH} 8.3,83$ $\mathrm{mM}$ boric acid, $1 \mathrm{mM}$ EDTA) at $100 \mathrm{~V}$. The gels were stained with $0.5 \mu \mathrm{g} / \mathrm{ml}$ ethidium bromide solution and visualized under alpha imaging system by comparing to 500bp of DNA ladder.

Table1. List of RAPD decamer primers used for molecular variation study

\begin{tabular}{|c|c|c|c|}
\hline Primer & Sequence $\left(5^{\prime}-3^{\prime}\right)$ & Primer & Sequence $\left(5^{\prime}-3^{\prime}\right)$ \\
\hline OPA 02 & TGCCGAGCTG & OPF 08 & GGGATATCGG \\
\hline OPA 04 & AATCGGGCTG & OPF 09 & CCAAGCTTCC \\
\hline OPB 03 & CATCCCCCTG & OPF 10 & GGAAGCTTGG \\
\hline OPF 03 & CCTGATCACC & OPF 13 & GGCTGCAGAA \\
\hline OPF 04 & GGTGATCAGG & OPF 14 & TGCTGCAGGT \\
\hline OPF 05 & CCGAATTCCC & OPF 15 & CCAGTACTCC \\
\hline OPF 06 & GGGAATTCGG & OPF 16 & GGAGTACTGG \\
\hline OPF 07 & CCGATATCCC & & \\
\hline
\end{tabular}

Data Scoring and Analysis

The RAPD bands were scored as present (1) or absent (0), each of which was treated as an independent character regardless of its intensity. Data analyses were performed using the NTSYS-pc (Numerical Taxonomy System, version 2.02, Rohlf, 2000). Analysis utilized the SAHN clustering programme of the NTSYS-pc package to construct an UPGMA (unweighted pairgroup method, arithmetic average) dendrogram for the genotypes. The SIMQUAL program was used to calculate the Jaccard's coefficient, a common estimator of genetic identity and was calculated as follows:

$$
\text { Jaccard's coefficient }=N_{A B} /\left(N_{A B}+N_{A}+N_{B}\right)
$$

Where, $N_{A B}$ is the number of bands shared by samples, $N_{A}$ represents amplified fragments in sample A, and $N_{B}$ represents fragments in sample B. Similarity matrices based on these indices were calculated.

\section{RESULT AND DISCUSSION}

\section{Pattern of Polymorphic Bands}

All the fifteen RAPD primers produced clear polymorphic amplification for the turmeric genotypes used in the study resulting 68 RAPD bands of which 59 bands were polymorphic with average polymorphism of $86.76 \%$. The polymorphism of the RAPD primers ranged from 50\% in OPA2 and OPF-14 to $100 \%$ in primers OPB 03, OPF 04, OPF 05, OPF 07, OPF 08 and OPF 09 while OPF 16 showed $83.33 \%$ polymorphism (Table 2 ). 
Mikias Damtew et al. "Genotyping of High Yielding Varieties and Genotypes of Turmeric (Curcuma Longa L.) using RAPD Markers"

The total number of markers amplified by the 15 primers ranged from 34 in genotype BSR-1 to 53 in genotype CL-213. The other genotypes showed a comparable number of amplification with genotypes CL-206, CL-219, PTS-8, PTS-10, BSR-2, CL-15, CL-101, and CL-193 recoded 42, 44, 45, 46, 49, 49, 49 and 49 markers respectively. The OPF series primers OPF-5 and OPF-9 failed to show any amplification for the genotype BSR-1. Similarly, the primers OPF-8 and OPF-4 did not produce band for the genotypes CL-219 and CL-206.

Table2. Sequence of RAPD primers with their amplification pattern for turmeric genotypes in the study

\begin{tabular}{|c|c|c|c|c|}
\hline Primer & Sequence (5' $\mathbf{3}^{\prime}$ ) & Total no. number of bands & $\begin{array}{c}\text { No. of polymorphic } \\
\text { bands }\end{array}$ & $\begin{array}{c}\text { Polymorphism } \\
(\mathbf{\%})\end{array}$ \\
\hline OPA 02 & TGCCGAGCTG & 4 & 2 & 50 \\
\hline OPA 04 & AATCGGGCTG & 4 & 3 & 75 \\
\hline OPB 03 & CATCCCCCTG & 2 & 2 & 100 \\
\hline OPF 03 & CCTGATCACC & 4 & 4 & 100 \\
\hline OPF 04 & GGTGATCAGG & 3 & 3 & 100 \\
\hline OPF 05 & CCGAATTCCC & 6 & 6 & 100 \\
\hline OPF 06 & GGGAATTCGG & 3 & 2 & 66.67 \\
\hline OPF 07 & CCGATATCCC & 5 & 5 & 100 \\
\hline OPF 08 & GGGATATCGG & 3 & 3 & 100 \\
\hline OPF 09 & CCAAGCTTCC & 3 & 3 & 100 \\
\hline OPF 10 & GGAAGCTTGG & 4 & 3 & 75 \\
\hline OPF 13 & GGCTGCAGAA & 8 & 5 & 62.5 \\
\hline OPF 14 & TGCTGCAGGT & 6 & 3 & 50 \\
\hline OPF 15 & CCAGTACTCC & 6 & 4 & 83.33 \\
\hline OPF 16 & GGAGTACTGG & 6 & 5 & \\
\hline
\end{tabular}

Similarity Patterns among Turmeric Clones

Jaccard's similarity between pairs of accessions ranged between 0.36 and 0.93 (Table 3) with a mean of 0.62. Prominent differences existed in the genetic similarities of the genotypes with BSR-1 and PTS-8 showed the least similarity index followed by BSR-1 and CL-101, 193 and 206 pair wise similarity indexes. The genotype CL-101 and CL-193 recorded the highest similarity index (0.93) followed by the combination BSR-2 and CL-101 (0.89). The lowest average similarity index was recorded by the variety BSR-1 (0.49) followed by PTS-8 (0.54) and CL-219 (0.58) (Table 3).

Table3. Jaccard's pair wise similarity in 10 C. longa (turmeric) genotypes.

\begin{tabular}{|l|l|l|l|l|l|l|l|l|l|l|l|}
\hline & $\begin{array}{l}\text { BSR } \\
\mathbf{- 1}\end{array}$ & $\begin{array}{l}\text { BSR } \\
\mathbf{- 2}\end{array}$ & $\begin{array}{l}\text { PTS } \\
\mathbf{- 8}\end{array}$ & $\begin{array}{l}\text { PTS } \\
\mathbf{- 1 0}\end{array}$ & $\begin{array}{l}\text { CL- } \\
\mathbf{1 5}\end{array}$ & $\begin{array}{l}\text { CL- } \\
\mathbf{1 0 1}\end{array}$ & $\begin{array}{l}\text { CL- } \\
\mathbf{1 9 3}\end{array}$ & $\begin{array}{l}\text { CL- } \\
\mathbf{2 0 6}\end{array}$ & $\begin{array}{l}\text { CL- } \\
\mathbf{2 1 3}\end{array}$ & $\begin{array}{l}\text { CL- } \\
\mathbf{2 1 9}\end{array}$ & Average \\
\hline BSR-1 & 1.00 & 0.44 & 0.36 & 0.61 & 0.65 & 0.43 & 0.44 & 0.45 & 0.55 & 0.54 & 0.49 \\
\hline BSR-2 & & 1.00 & 0.55 & 0.58 & 0.67 & 0.89 & 0.87 & 0.73 & 0.67 & 0.58 & 0.66 \\
\hline PTS-8 & & & 1.00 & 0.50 & 0.53 & 0.57 & 0.58 & 0.58 & 0.54 & 0.54 & 0.54 \\
\hline PTS-10 & & & & 1.00 & 0.80 & 0.60 & 0.61 & 0.55 & 0.76 & 0.67 & 0.61 \\
\hline CL-15 & & & & & 1.00 & 0.62 & 0.64 & 0.68 & 0.69 & 0.57 & 0.61 \\
\hline CL-101 & & & & & & 1.00 & 0.93 & 0.68 & 0.69 & 0.57 & 0.64 \\
\hline CL-193 & & & & & & & 1.00 & 0.70 & 0.70 & 0.58 & 0.65 \\
\hline CL-206 & & & & & & & & 1.00 & 0.64 & 0.55 & 0.64 \\
\hline CL-213 & & & & & & & & & 1.00 & 0.66 & 0.65 \\
\hline CL-219 & & & & & & & & & & 1.00 & 0.58 \\
\hline $\begin{array}{l}\text { Total No. Of } \\
\text { bands }\end{array}$ & \multirow{2}{*}{34} & 49 & 45 & 46 & 49 & 49 & 49 & 42 & 53 & 44 & \\
\hline
\end{tabular}

Clustering of the Turmeric Clones

The present RAPD studies revealed relatively distinct clustering pattern among the genotypes. The variety BSR-1 was grouped distinctly different from other genotypes, while the rest of the genotypes viz. CL-206, CL-219, PTS-8, PTS-10, BSR-2, CL-15, CL-101, CL-193 and CL-213 were classified in the second cluster. The second cluster was further divide in to 3 groups. The genotype PTS- 8 was grouped alone. The genotypes PTS-10, CL-15, 213 and 219 were grouped together. In the same cluster variety BSR-2, CL-101, CL-206 and CL-193 were grouped together. 
Mikias Damtew et al. "Genotyping of High Yielding Varieties and Genotypes of Turmeric (Curcuma Longa L.) using RAPD Markers"

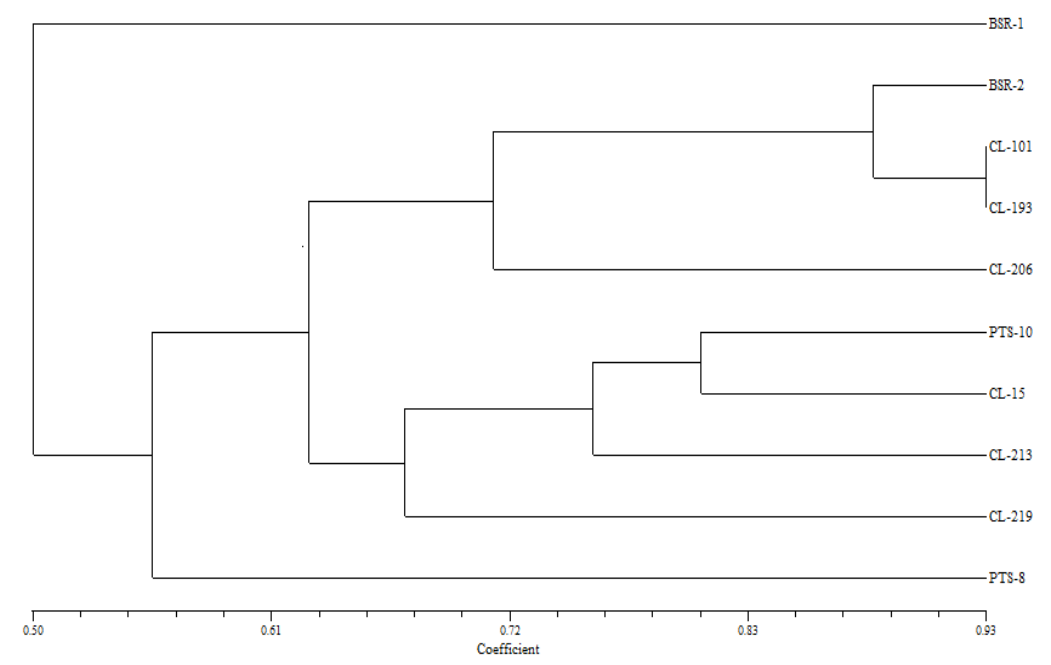

Figure1. Dendrogram of 10 turmeric genotypes resulting from a UPGMA cluster analysis obtained from 15 RAPD primers.

\section{Diversity Analysis with RAPD Marker}

The evaluation of genetic diversity and construction of linkage maps would promote the efficient use of genetic variations in the breeding program (Paterson et al., 1991) and provides an opportunity to characterize genotypes and to measure genetic relationships more precisely than other markers (Soller and Beckmann, 1983).

The presence of high polymorphism in the study is in line with several documented results by the use RAPD primers indicating the robustness of the marker system used for genetic variation analysis among the turmeric clones. Polymorphic nature of RAPD bands accounts for the intra-specific genetic variation known to occur in the C. longa L. (Sasikumar and Syamkumar, 2007; Islam et al., 2005; Paisooksantivatana et al., 2001; Nayak et al., 2006; Siju et al., 2010 and Paisooksantivatana and Thaikert, 2009) and significant genetic variations by RAPD markers have also been reported in other species at cultivar level (Huang et al., 2003). The causes of these genetic variations in the genus Curcuma is suggested by different authors: aneuploidy is reported for some Curcuma species (Eksomtramage et al., 2002) and geographically isolated population also accumulates genetic differences as they adapt to different environment (Paisooksantivatana et al., 2001). Amsalu et al., (2000) also concluded that the clustering pattern of the regions of origin by RAPD markers was broadly concordant with cultivars grown in similar agro-climatic conditions. Since the difficulties pertaining to hybridization in turmeric, it can be assumed that the difference in genetic distance between the genotype PTS-8, supposed to be originated from Potangi region as opposed to Erode region with the rest of the genotypes might be attributed to differentiation through adaptation phenomenon.

\section{CONCLUSION}

The RAPD marker result depicted that the use of such molecular marker tool could be a viable option in the presence of a validated marker system developed for identification of the genotypes. In the present study the presence and absence of some specific markers were observed in the primer OPF 05 for distinguishing the genotypes PTS-8 and PTS-10 which are believed to arise from same region. The marker size $\sim 1 \mathrm{~kb}$ and $\sim 400 \mathrm{bp}$ were present for the genotype PTS- 8 which were absent in the genotype PTS-10 in a reverse manner a marker size $\sim 200 \mathrm{bp}$ was present in the genotype PTS-10 while not PTS8 indicating that the use of these primers is a very viable option for identification of single genotypes.

\section{REFERENCES}

[1] Amsalu, A., Bryngelsson T. and Endashaw B. 2000. Genetic variation of Ethiopian and Eritrean sorghum (Sorghum bicolor (L.) Moench) germplasm assessed by random amplified polymorphic DNA (RAPD). Genetic Resources and Crop Evolution 47: 471-482.

[2] Chandra, R., Desai A.R., Govind S. and Gupta P.N. 1997. Metroglyph analysis in turmeric (Curcuma Longa L.) germplasm in India. Scientia Horticulturae 70. 211-212. 
Mikias Damtew et al. "Genotyping of High Yielding Varieties and Genotypes of Turmeric (Curcuma Longa L.) using RAPD Markers"

[3] Cousins, M., Adelberg J., Chen F. and Rieck J. 2007. Antioxidant capacity of fresh and dried rhizome from four clones of turmeric (Curcuma longa L.) grown in vitro. Indust. Crops Prod. 25: $129-135$.

[4] Doyle, J. J., Doyle J. L. 1987. A rapid DNA isolation procedure for small quantities of fresh leaf tissue, Phytochem Bull 19: 11-15.

[5] Eksomtramage L., Sirirugsa P., Jivanit P. and Maknoi C. 2002. Chromosome counts of some Zingiberaceae species from Thailand. Songklanakarin J. Sci. Tech. 24: 311-319.

[6] Hamrick, J. L. and Loveless M. D. 1989. The genetic structure of tropical tree populations, association with reproductive biology. In: Bock J.H. and Linhart Y. (Eds), The Evolutionary Ecology of Plants. Westview Press, Boulder, pp. 129-146.

[7] Harini, S. S., Leelambika M., Kameshwari M. N. and Sathyanarayana N. 2008. Optimization of DNA isolation and PCR-RAPD methods for molecular analysis of Urgenia indica kunth. IJIB, Vol. 2(2). 138-144.

[8] Huang, H., Layne D. R. and Kubisiak T. L. 2003. Molecular characterization of cultivated pawpaw (Asimina triloba) using RAPD markers. J. Amer. Soc. Hort. Sci. 128: 85-93.

[9] Islam M.A., Meister A., Schubert V., Kloppstech K. and Esch E. 2007. Genetic diversity and cytogenetic analyses in Curcuma zedoaria (Christm.) Roscoe from Bangladesh. Genetic Resources and Crop Evolution 54:149-156.

[10] Kurian, A. and G.S. Nair. 1996. Evaluation of turmeric types for yield and quality. Indian J. Pl. Genet. Resources, 9(2): 327-329.

[11] Nayak, S., Naik P.K., Acharya L.K. and Pattnaik A.K. 2006. Detection and evaluation of genetic variation in 17 promising cultivars of turmeric (Curcuma Longa L.) Using 4C Nuclear DNA Content and RAPD Markers. Cytologia 71: 49-55.

[12] Paisooksantivatana Y., Kako S. and Seko H. 2001. Genetic Diversity of Curcuma Alismatifolia Gagnep (Zingiberaceae) in Thailand as revealed by allozyme polymorphism. Genetic Resources and Crop Evolution 00: 1-10.

[13] Paisooksantivatana, Y. and Thaikert R. 2009. Variation of Total Curcuminoids Content, Antioxidant Activity and Genetic Diversity in Turmeric (Curcuma longa L.) Collections. Kasetsart J. (Nat. Sci.) 43 : 507 - 518.

[14] Paterson A. H., Tanksley S.D., and Sorrells M. E.1991. DNA markers in plant improvement. Adv Agron 46:39-90.

[15] Philip, J. and Nair, P.C.S. 1983. Morphological and yield characters of turmeric types. Indian Cocoa, Arecanut Spices J., 6(3): 61-68.

[16] Rohlf, F. J. 2000. NTSYSpc: Numerical Taxonomy and Multivariate Analysis System, version 2.02. Exeter Software, New York.

[17] Roses, I. A. 1999. Curcuma longa in Medicinal Plants of The World, Chemical Constituents, Traditional and Modern Medical Uses. Human Press, Totuwa, New Jersey, pp. 139-153.

[18] Sasikumar B. and Syamkumar S. 2007. Molecular marker based genetic diversity analysis of Curcuma species from India. Scientia Horticulturae 112: 235-241.

[19] Siju, S., Dhanya K., Syamkumar S., Sasikumar B., Sheeja T. E., Bhat A. I. and Parthasarathy V. A. 2010. Development, Characterization and Cross Species Amplification of Polymorphic Micro-satellite Markers from Expressed Sequence Tags of Turmeric (Curcuma longa L.). Mol Biotechnol 44:140-147.

[20] Soller M., Beckmann J. S. (1983) Genetic polymorphism in varietal identification and genetic improvement. Theor. Appl. Genet. 67:25-33. 